ALLAN, Barbara. Supporting Research Students. London: Facet Publishing. 2010.

192 pages. ISBN 978-1-85604-685-5. $£ 44.95$

With the increasing profile of the research training agenda, many academic libraries have taken the opportunity to revisit their practices in supporting researchers. Some libraries have a dedicated research support role vested in a single person or small team; others have incorporated research support within liaison librarian portfolios. This book will interest both groups, and especially those who are new to supporting research students.

The book has nine chapters. The first five chapters address the nature of research and research processes, the research student's experience and research skills training; chapters 6 and 7 describe academic libraries' approaches to supporting research students, both face to face and online; and the remaining two chapters discuss research communities and professional development for library and information staff respectively. The author states that individual chapters may be read and used in any order.

The book is well signposted. With a clear description of the book's structure in chapter one, an introduction to each chapter as it starts, and a summary of each chapter at its end, one knows exactly what is there. Chapters are divided into sections of moderate length, each dealing with a different aspect of the topic. Good use is made of bullet pointed lists. Several case studies are used to good effect. These include a study of the types of information source used by students; an example session plan for teaching referencing; a six week training course provided for research students by library staff; and a description of the development of a Virtual Graduate School.

The earlier chapters are informed by the author's recent experience as a research student completing a professional doctorate, and by her discussions with members of both the research community and the library and information professions. This has obviously given her a good understanding of some of the basic issues in research student life. There is recognition of the variety and complexity of the research student experience, although many examples come from the social sciences. These chapters offer a valuable insight into the context of research student support, but the reader is mostly left to make their own connections between the issues discussed and their impact (in practical terms) on the provision of research support services.

Chapters six and seven are the heart of the book. They are stuffed full of useful examples of how research students are being supported in academic libraries. There are lists showing types of support; induction activities; one to one services; online services and targeted support. A self-assessment checklist at the end of chapter six allows the reader to evaluate their own provision and reflect on areas for development. Chapter seven, focused mainly on the University of Hull's virtual graduate school and research environment, takes online provision of research support services to the next level. Incorporating the latest in web 2.0 technology, the virtual graduate school described here enables research students to interact with a range of resources, including blogs, wikis, podcasts and videos, 
and to communicate with their supervisors and each other. Like the earlier chapters, this chapter presents the information and allows the reader to reflect for themselves how this might be applied in their own institution.

Chapter eight cleverly mops up a number of other topics of relevance to supporting research students. Under the umbrella of 'research communities' the author discusses communities of practice and interest; information sharing in academic communities; professional associations; academic conferences and online networking. It is unfortunate that the 'implications for library and information workers' are sidelined to less than one page at the end of the chapter.

The final chapter addresses for professional development for those responsible for research student support. A distinction is drawn between academic research and the investigative workplace project. A list of professional organisations and networks is given. Although CILIP's 'specialist groups' are mentioned, it would have been good to see specific reference to the University, College and Research Group (UC\&R) and the Library and Information Research Group (LIRG), both of these groups are active in undertaking or supporting research. The JISCmail LIS-RESEARCHSUPPORT mailing list is another omission.

Overall this book is a good starting point for somebody newly tasked with supporting research students and it has sufficient detail to have some interest to a more experienced librarian. As a practical guide, chapter 6 ticks all the boxes. There are more trivial typographic errors than one normally expects from Facet Publishing (e.g. pages 58, 61, 83, 103, 146, 149 and 174) but these shouldn't detract from the value of the book which fills a useful gap in the literature. I shall be encouraging my colleagues in both the library and our Graduate School to take a look.

\author{
Miggie Pickton \\ Research Support Specialist \\ The University of Northampton \\ miggie.pickton@northampton.ac.uk
}

\title{
Open access and copyright
}

Library and Information Research is an open access journal. A freely available copy of this paper may be downloaded from the journal's website: http://www.cilipjournals.org.uk/lir

Copyright and associated moral rights in works published in Library and Information Research are retained by the author(s) but this paper may be used freely, with proper attribution, in educational and other non-commercial settings. 